\section{THE POST OFEICE AND THE PREVENTION OF TUBERCULOSIS.}

\section{BY CHARLES H. GARLAND.}

IT is a matter of which the Post Office can be rightly proud that the better recognised forms of contagious disease are rare among the huge staff of employés. The fact reflects some credit on the methods adopted for exclusion and disinfection. But the same fact brings into remarkable prominence the entire lack of organisation for the prevention of tuberculosis. In giving evidence in 1895 before a committee presided over by Lord Tweedmouth I tendered facts to prove that there was a relatively high mortality from phthisis among at least one section of the postal employés and prepared tables to illustrate my contentions. Although these tables have been given an improper significance in the popular press-a significance which I never desired to attach to them-I still think they are nevertheless indicative of a very serious condition of affairs. The fioures were drawn from the reports of an insurance society which is confined entirely to Post Office rofficials, and the membership is sufficiently numerous to be typical of the whole staff. The present membership numbers 19,180. The tables, which were based on 10 years' returns, showed that of every 100 deaths amono sorting-clerks and telegraphists between the ages of 15 and 65 years, $45 \cdot 4$ were due to phthisis. This high percentage may be due in part to the exclusion of other diseases, but the significance from our present standpoint lies in the fact that although tuberculosis is so eminently preventable, nevertheless so large a percentage of the deaths is caused by it. It was contended, in reply to these figures, that the membership of the insurance society from which the figures were drawn consisted of damaged lives. I have looked carefully into this contention but see no reason for doubting the substantial accuracy of the figures. It is true that the deathrate among the members of the society is higher than among the postal staff as a whole, but the higher mortality is adequately accounted for by the fact that whilst the postal staff includes an immense number of employés between the ages of 15 and 30 years a very small percentage joins the insurance society before 30 years of age. The mortality of the society thus misses the leaven of the period of low mortality.

The ratio of deaths from phthisis to the total mortality does not, of course, necessarily mean a high mortality, but an examination of official figures for the whole postal staff will show that the mortality from tuberculous disease is absolutely as well as relatively high. Following upon the evidence tendered to the Tweedmouth Committee tables were given in the annual report of the Postmaster-General showing the deaths from phthisis and the superannuations from the same cause. The official figures published under these heads show that the mortality from tuberculous disease is appreciably higher among the postal staff than among the general populace. From the figures supplied during the years in which information was given I have constructed the following table. It refers to the whole of the established postal staff, male and female, and covers the whole of Great Britain and Ireland:-

Table showing Loss from Phthisis.

\begin{tabular}{c|c|c|c|c|c|c}
\hline Year. & Staff. & $\begin{array}{c}\text { Deaths } \\
\text { from } \\
\text { phthisis. }\end{array}$ & $\begin{array}{c}\text { Retire- } \\
\text { ments } \\
\text { frem } \\
\text { phthisis. }\end{array}$ & Total. & $\begin{array}{c}\text { Loss per 1000 } \\
\text { living in } \\
\text { the Postal } \\
\text { Service. }\end{array}$ & $\begin{array}{c}\text { Loss per 1000 } \\
\text { living in } \\
\text { the general } \\
\text { populace. }\end{array}$ \\
\hline 1896 & 62,852 & 86 & 67 & 153 & $2 \cdot 4$ & $\cdots$ \\
1897 & 76,866 & 72 & 80 & 152 & $1 \cdot 9$ & $1 \cdot 3$ \\
1898 & 79,121 & 70 & 87 & 157 & $1 \cdot 9$ & $1 \cdot 3$ \\
1899 & 82,172 & 62 & 83 & 145 & $1 \cdot 7$ & $1 \cdot 3$ \\
\hline
\end{tabular}

In this table I have added together the deaths and the cases of retirement from phthisis. Knowing the conditions of retirement in the Post Office, it is impossible to suppose that an appreciable number of those retired escape death. Retirement is, in fact, indicative of imminent decease. In each of the four years recorded the loss from phthisis is higher than the mortality of the general populace from the same disease. But there are considerations which make this loss even more serious than is at first apparent. Every life in the Post Office is a selected life. As a commentary on the above table it is sufficient to take one or two statements made by Postmasters-General. In the forty-first report 1895, the Postmaster-General says: "The Post Oftice staff consists of selected lives, candidates being required to pass a medical examination before ther are admitted to the public service," and in the forty-second report the following words occur: "In the Post Office there ought to be a smaller number of deaths per 1000 than would be found in a similar number of persons engaged in somewhat similar occupations elsewhere." I should hare liked to compare the mortality of the Post Office with similar trades had it been possible. But the Port Office is a congeries of trades and professions and the official figures are not classified. The whole are lumped together as though the employés were one uniform class performing identical work under identical conditions. The need for some classification will be obvious from the following description of the staff and its work culled from the Postmaster-General's fort-f-first report. "The Post Office population is distributed unequally among different ages and between both sexes, excluding the very young and very old. It consists of selected lives, candidates being required to pass a medical examination before they are admitted to the public service, and the nature of the work varies from duties of a light and pleasant character to some which involve strain, exposure, and break of rest." Apart from the selection of lives this description would more accurately fit the general populace than any single trade or profession. So I propose that the figures should be compared with the mortality from phthisis among the general populace ; compared in this way it is found that the loss from phthisis among the selected lives of the Post Office is appreciably higher than the loss among the gencral populace, which stands at about 1.3 per 1000 living.

As there seems to be a progressive decrease in the loss from phthisis in the Post Office from 1896 to 1899 it is well to mention that a decrease not shown in the first decimal place occurred in the general mortality. The decrease in the Post Office was not entirely due to any new precautionary measures. The table which I have given shows, however, that there was a progressive increase in the number of retirements after the evidence given in 1895 and a corresponding diminution in the number of deaths, a fact which proves how close is the relation between the two sets of figures and fully justifies my method of computing the total loss from phthisis.

It would be a work of supererogation to endeavour to prove that such a condition of affairs requires attention, nor is it necessary to dwell on the facilities which exist for prevention in a department organised and controlled like the Post Office. It is surely the duty of the State to lead the way in the adoption of preventive measures and by force of example to urge other large employers to adopt like measures. Yet it is safe to affirm that practically no measures are used to prevent tuberculosis in the Post Office. In the General Post Office itself it would be difficult, if not impossible, to find a single spittoon or a prohibition against expectoration. Speaking from personal observation I can say that even known consumptives openly and freely expectorate in all parts of the galleries where the minor establishment worksdust is allowed to accumulate on the walls and to remain for months and even years. All the buildings of the postal department must be contaminated. Even the ventilation is left to the haphazard whims of the employés instead of being in charge of a properly qualified officer. I have reason to believe that some classes of the work especially predispose to phthisis but it is enough for my purpose to show that absolntely no preventive measures exist in the buildings where any class of work is performed.

This lack of precaution is especially striking in view of what has been done in the French Post Office. As the conditions are so markedly analogous I will refer to the report recently presented to the Minister of Commerce by $\mathrm{Dr}$. Mignot upon the application of preventive measures to the postal and telegraph departments, and the decrees issued for the purpose of giving practical effect to his recommendations. Basing his report on the conclusions of the Commission on Tuberculosis, Dr. Mignot says: "The Commission was occupied for some time in considering the danger arising from this contagion among more or less numerous bodies of 
men working in common in a limited space. A single tuberculous subject soiling the floor with his expectorations will then render the place of work dangerous for years to come, and communicate his disease to hundreds of others. But this danger can be reduced almost to nothing by a series of protective measures. The enemy is well known and the means of combating him are sure. In this struggle corporate bodies, and especially state corporations, have effective arms at their disposal; and, in addition, it is their duty to set an example and to instruct by their example. During the year 1899, out of nearly 71,000 employés of different grades in the posts and telegraphs of France 200 were certified as having died from tuberculosis, and 88 were retired on account of the same complaint, making a mortality of $28 \cdot 1$ per 10,000 , and a loss from tuberculosis of 40 per 10,000 , for it cannot reasonably be supposed that a rery large number of those retired escaped death. The general mortality from all diseases during the years 1897, 1898 , and 1899 was 1557 , and the number of deaths from tuberculosis 561, without reckoning retirements, or about 36 per cent. - that is to say, out of 100 deaths tuberculosis causes 36. At first sight this mortality does not appear excessive. It is higher, however, than the average in France, which is 34 deaths from tuberculosis in 10,000 inhabitants instead of 40 per 10,000 for the postal and telegraph employés. It must be remembered that the postal and telegraph employés undergo a medical examination before admission, which excludes the weak and sick. In these circumstances the mortality should be below the average, yet it seems to be sensibly above it. This fact is much plainer when we take the figures for a single department of the Seine. In 1899, ont of 1500 employés 43 died and 50 were retired on account of tuberculosis, or a loss of 62 per 10,000 . The general mortality from tuberculosis in Paris is 49 per 10,000 ."

Dr. Mignot's refort recommends certain preventive measures. First, there are the measures concerning the buildings, and second, the measures concerning the staff. The first set of measures can be thus summarised. It is of the first importance to prevent as far as possible the contamination of the buildings. It should be easy to teach the staff that in the offices contagion is caused exclusively by expectorations, which dry and mix with the dust of the air and penetrate into the lungs. Thus, every tuberculous subject who spits on the floor sows death among his comrades. A corollary would be the absolute prohibition of spitting except in hygienic spitoons, a sufficient number of which should be placed in convenient spots. This prohibition should extend to the vestibules, corridors, cloakrooms, water-closets, staircases, and even to the courtyards of the department. Having taken precautions against contamination of the buildings it must be remembered that the majority of them are already contaminated, and that despite precautions new contaminations may occur. In every office where the presence of a tuberculous subject has been reported a careful disinfection should take place. It is absolutely essential to change the daily method of cleaning the offices. We know that only dried expectorations are dangerous; and dry sweeping, or nearly dry sweeping, as it is now practised, is a perfect method of disseminating them in the air. In every building where tuberculous subjects can spit on the floor the broom is a terrible engine of death. It is absolutely essential to replace sweeping by washing with damp cloths in the manner now employed in barracks, and more recently at police-stations. Beyond the daily cleaning with damp cloths it wonld be well to have a thorough weekly washing; the ideal method would be to wash not only the floors but also the walls and ceilling. To be perfectly efficacious the washing presupposes the impermeability of the floors. The methods of obtaining this result are numerous and some of them extremely cheap. The flooring of the offices should be rendered impermeable and especially the floors of those offices into which the public are admitted. In the latter a thorough washing with water every day should be prescribed. No building of the department at present possesses the least organisation for avoiding tuberculous contagion; not one, even among the newest, shows any sign of the consciousness of the danger. Everywhere are to be found angles, corners, open-work iron beams, and lustres of complicated ornamentation, carefully storing the injurious dust that a current of air will later on scatter upon the heads of the employés. Everywhere are walls, ceilings, and floors difficult or impossible to wash. Everywhere are dark colours which hide the dirt.
The second set of recommendations deals first with the rigid exclusion of tuberculous subjects and tuberculous suspects by a more searching examination. We must, says Dr. Mignot, prevent tuberculous subjects from entering the service of the department, eliminate and treat all those who are already there, and give to all the employés special instruction by which they will be able the better to avoid contagion. He then goes on to plead for a better statistical system and the more accurate description of complaints in the certificates and registers. The department should know its invalids and the complaints from which they suffer. Knowing them it is necessary to treat them. I sanatorium alone can procure everything indispensable to their cure. This will involve a tolerably heavy expense, for the number of tuberculous patients must be equal to at least three or four times the number of dying or retired annually. There must be from 900 to $1 \mathrm{CO}$ for the whole of France, and 300 to 400 for the Department of the Seine alone. The daily expense for a consumptive patient in hospital is about $4 \mathrm{f} .50 \mathrm{c}$., reckoning the capital sunk in the establishment. In addition. for married patients with a family there must be reckoned an allowance of not less than 1f. 50c. per day. (These figures are those of the popular sanatoria of Germany.) "Nevertheless," goes on the report, "we cannot allow consumptives in the earlier stages of their complaint, and quite curable, to die without hope. We cannot condemn to nearly certain death hundreds of men often infected during their work and by their work. Still less can we, as at present, not only not treat them, but allow them to spread contagion and death in the ranks of their comrades."

Finally, it is necessary to teach the employés the causes and modes of propagation of tuberculosis. Printed notices should be distributed to all the staff. Very succinctly they should be told how the bacilli of tuberculosis thrown on the floor in the sputum of consumptives dries and mixes with the dust of the air, penetrating the lungs during inspiration and there developing and producing tuberculous lesions. It should be explained how easy it is to avoid contagion it each of them individually will observe carefully the hygienic measures above described.

Following on this report decrees were immediately issued giving effect to all its recommendations, and a most concise and lucid notice ${ }^{1}$ was issued to every member of the staffs and posted prominently in all parts of the buildings.

I have quoted lengthily from this report in order to show how an analogous set of circumstances was treated in France. The report deals with the same classes of work and workers and the administration has to encounter the same difficulties as the English administration. In addition the report sets forth plainly and simply the necessary precautions which should be taken in England. The large administrations employing vast numbers of men and women should be made to realise the sacred responsibility which the lives of these men and women represent. A life sacrificed to a preventable disease is a wasted life. If no precaution is taken against the disease a heavy part of the responsibility must rest with the administration.

1 This notice is so striking and yet so brief that it would not we out of place to append a translation :- "Notice Concerning the Propagation of Tuberculosis. - Tuberculosis kills in Paris alone over 13,cco person: every vear. In provincial towns and country districts it is far from rare. Nevertheless, it is known that it is caused entirely loy contagion; all the modes of contagion are known, therefore it is preventable. In nearly every case the propagation occurs in the following manner A tuberculous subject spits on the floor and the sputums dries. The microbes of tuberculosis are to be found in the sputum in myriads and when dry can remain alive for many years, always reary myriads and when dry can remain alive for many years, always ready to germinate like a seed. They mix with the dust of the air, and if this clust is drawn in during respiration the microbes penetrate into the lungs, develop there, and produce the risease. No age cr constitution is secure from these attacks. It is, therefore. in the ir terest of all to watch over the observance of the following precautions: 1 . It is strictly forbidren to spit on the floor in the buildings of the Post floors must be cleaned with damp cloths."

WATER-SUPPLY of WestBuRY. The new waterworks which have been recently erected at Westbury, Wiltshire, were formally opened on Sept. 4th. The cost of construction has been about $£ 13,000$.

Extension of the City OF Bath.-The City Council of Bath on Sept. 4th adopted the recommendation of a special committee that the city should enlarge its boundaries in order to include several populous suburbs. The population of Bath has decreased by 4000 during the past 20 years, whilst that of the surrounding districts has increaser? by 12,000 . 